\title{
Aerial Biomass and Nitrogen Estimation of Emerged and Floating Macrophytes using Optical Remote Sensing: A Non-Destructive Method
}

Jessica Cristina Carvalho Medeiros ( $\sim$ jcc-bio@hotmail.com )

Universidade de Sao Paulo Campus da Capital https://orcid.org/0000-0003-0221-1736

Maurício Perine

Universidade de Sao Paulo Campus de Sao Paulo: Universidade de Sao Paulo

Marcelo Pompêo

Universidade de Sao Paulo Campus de Sao Paulo: Universidade de Sao Paulo

Marisa Bitencourt

Universidade de Sao Paulo Campus de Sao Paulo: Universidade de Sao Paulo

\section{Research Article}

Keywords: Aquatic plant, Biological invasion, Field measurements, RedEdge, Sentinel-2 bands simulation, Spectral signature, Spectroradiometry.

Posted Date: July 10th, 2021

DOI: https://doi.org/10.21203/rs.3.rs-691078/v1

License: (c) (i) This work is licensed under a Creative Commons Attribution 4.0 International License. Read Full License 


\section{Abstract}

Freshwater resources faces threats with aquatic plants invasion, considered biological pollution with deep effects on water quality and nutrients cycling due to their rapid growth. Orbital remote sensing has been an effective instrument of monitoring large water bodies. Thus, the aim of this study was to analyze the relation between reflectance and field measurements (biomass and nitrogen concentration) of aquatic plants to develop estimation equations and to test vegetation indices to use in orbital remote sensing. The most common tropical infesting species (Salvinia auriculata, Pistia stratiotes, Eichhornia crassipes and Eichhornia azurea) were collected during a year, measured their spectral response to simulate satellite bands, and the biomass and nitrogen concentration measurements. The bands intervals of Sentinel-2 satellite were choosing to the simulation due to their narrow bands and the RedEdge new band. The obtained field data were correlated with the reflectance obtained from spectroradiometry of each species and the equations showed $R^{2}=0.64$ to estimate biomass and $R^{2}=$ 0.60 to estimate nitrogen using the entire spectrum. Several indices described in the literature were tested with different Sentinel-2 bands but with no significant results. The NDVI index showed a separation among species using RedEdge band and can be used to identify the species, but not to estimate their biomass.

\section{Declarations}

- Ethics approval and consent to participate

Not applicable.

- Consent for publication

Not applicable.

- Availability of data and materials

The datasets used and/or analyzed during the current study are available from the corresponding author on reasonable request.

- Competing interests

The authors declare that they have no competing interests.

- Funding

This research was funded by Fundação de Amparo à Pesquisa do Estado de São Paulo (FAPESP) 2016/24528-2; 2019/10845-4), and Coordenação de Aperfeiçoamento de Pessoal de Nível Superior (CAPES) in grant support during the PhD program of the first author.

- Authors' contributions 
Conceptualization: all authors; methodology: all authors; validation: all authors; formal analysis: JCCM, MDB and MP; investigation: all authors; resources: MLMP; writing-original draft preparation: JCCM; writing-review and editing: MDB and MLMP; visualization: all authors; supervision: MDB and MLMP; funding acquisition: MLMP.

- Acknowledgements

The authors are grateful to all who contributed in the field and in the laboratory; to Roberto Shimizu, Ana Lúcia Brandimarte and to the anonymous reviewers for their valued comments.

\section{Introduction}

Aquatic macrophytes play an important role in the aquatic ecosystem balance (Esteves 2011; Pompêo 2017). However, the misuse of water resources by man, mainly in reservoirs for multiple urban uses, favor rapid plant growth that become aquatic weeds which harmed water quality. This condition needs constant monitoring of biological parameters, which is a fundamental component in freshwater resources management.

The pollutants release, deforestation, urban growth in the surroundings and dams contributes with a high concentration of organic matter in water, creating ideal conditions for aquatic plants spread, becoming invasion aquatic weeds (Jampeetong and Brix 2009; Julien et al. 2002; Sullivan et al. 2011). Some infecting of emerged and floating species is so agglomerated that could be misinterpreted as an island. The infestation became a biological pollution with significant effects on water quality, since disturbs the ability to alter nutrient cycling and the ecological functioning, creating harmed consequences for ecosystem and public health. This is why managers need fast and consistent techniques to monitor infestation condition taking preventive and/or remedial actions (Pompêo 2017).

Optical remote sensing of freshwater resources is increasingly becoming important to monitoring macrophytes infestation, especially the submerged ones (Ni et al. 2020; Rotta et al. 2018). There are few studies with emerged and floating plants, but these species cause infestations that normally occupy enormous areas, becoming similar to "crowded mats" on water surface (Coelho et al. 2005). Groundbased measurements provide the most direct and accurate distribution and quantity of aquatic weeds, but they are time-consuming, labour-intensive and spatially limited. So, the availability of satellite data provides great potential for the spatial and temporal monitoring of aquatic plants in a timely and costeffective approach (Dube et al. 2017).

The spectral response of vegetation enables to separate species and can be transformed into mathematical vegetation estimation models (Ferwerda et al. 2005; Ponzoni et al. 2012; Tian et al. 2011; Ullah et al. 2012). Absorption characteristics of plants can be incorporated in these empirical models using vegetation indices (VIs) to identify stress, biomass, productivity and other biophysical traits (Ghosh et al. 2016; Rotta et al., 2018). Most of the infestations shows one predominant specie and detecting it could be very helpful for the managers. Also, the estimation of biophysical parameters enables large 
scale of aquatic weeds monitoring, which would not be possible using the more expensive and timeconsuming ground-based measurements. The repeated coverage of satellite sensors provide data for long-term monitoring, which is crucial in identifying the success of controlling measures of aquatic weeds (Penatti et al. 2015).

Many indices have been used to better estimate aerial biomass and nitrogen leaves concentration (Wang et al. 2016). All of them use the spectral bands Blue, Green, Red, Red Edge, and Near Infrared (Ferwerda et al. 2005; Ponzoni et al. 2012; Tian et al. 2011; Ullah et al. 2012). Since the Red Edge (RE) vary within species, Aparicio 2007 calculated it for twelve macrophytes using radiometric data, in order to simulate their spectral signatures registered by satellites. However, there are few studies that test vegetation indices $(\mathrm{VI})$ in aquatic macrophytes, estimating biophysical and biochemical parameters in an infestation area using reflectance, that can be faster and less expensive to vegetation measurements. In addition, the launch of satellites with new spectral bands, such as RE and other subdivisions of the near infrared (NIR), brings the need to carry out new tests.

Wang et al. (2016) made a diversified bibliographic review of aerial biomass $(\mathrm{VI})$ and nitrogen leaf concentration indices $(\mathrm{NI})$ based on radiometric data. Those indices are mathematical models that use reflectance percentage to estimate vegetation parameters (Peñuelas et al. 1993; Clevers et al. 2002; Cho and Skidmore 2006; Zhao et al. 2007; Dash and Curran 2007; Dusseux et al 2015). The advantages of using indices are to standardize the analyses allowing future comparisons. There are several studies that evaluate and quantify the relationships between linear combinations of vegetation indices and biomass (Motohka et al. 2010; Rotta et al. 2018). Most studies calculate the indices from images obtained by the satellite (Silva et al. 2010; Dube et al. 2017), but there are few studies that perform this estimation through the field collection, measuring radiometry directly from the plant, doing the opposite way. Also, other studies observe spatial variability of macrophyte cover, but there are no studies estimating biomass or nitrogen concentration in an infestation condition. Rotta et al. (2018) discuss that models with more field data can enhance the accuracy to periodically map aquatic vegetation height and biomass. The existence of various indices enables to find relationships between field, laboratory and satellite data, but they need to be tested on emerged and floating aquatic plants using bands from multispectral satellite that have rarely been used.

For a large-scale modeling of biophysical and biochemical parameters to be successful, it is necessary to: 1 ) correct selection and application of remote sensing; 2 ) that is coupled with the field data for calibration and validation; 3 ) and that is integrated with an appropriate mathematical modeling (Barbosa et al. 2014). The Sentinel-2 satellite includes a Multi-Spectral Instrument (MSI) and has been used in monitoring the earth surface characteristics. This innovative equipment captures high-resolution images with 13 spectral narrow bands for a new view of the soil and vegetation. Studies have shown that indices calculated from narrow bands improve the estimation of several vegetation parameters (Gong et al. 2003; Lee et al. 2004; Mutanga and Skidmore 2004). In addition, data obtained through Sentinel-2 can be used to evaluate biomass every 5-10 days (Dusseux et al. 2015), improving the difficulties of field sampling and the consistency in collecting data for management. Sentinel-2 satellite was the first optical Earth 
observation satellite to have three spectral bands located in the "red edge" band, providing important information about the state of plants, although these bands have not been commonly used, compared to the remaining bands ( $\mathrm{Ni}$ et al. 2020). So, this satellite can be used to discriminate and classify invasive plants.

In the case of emerged and floating macrophytes, it is important for managers facing infestation issues that new models are made and indices are tested to estimate biomass and nitrogen concentration, in order to collect information for better decisions. It is necessary that this collection is not expensive, labour-intensive (non-destructive) and time consuming as ground-based measurements. Therefore, the aim of this study is to calculate models and to test indices that estimate aerial biomass and nitrogen leaves concentration of emerged and floating macrophytes obtained in the field, using their reflectance measured in the laboratory, simulating satellite observation. For that, the range spectral used for simulation is from satellite Sentinel-2, with narrow spectral bands and RedEdge band included.

\section{Materials And Methods}

The emerged and floating macrophyte species chosen for this study are the most common infesting in Brazilian reservoirs, especially those surrounded by urban areas: Salvinia auriculata, Pistia stratiotes, Eichhornia crassipes e Eichhornia azurea (Pompêo 2017). Except for S. auriculata, the other four species were already studied and had calculated the RedEdge Position for each species (Aparicio 2007; Aparicio and Bitencourt 2015).

A diversity of samples of each species was collected to estimate biomass and nitrogen concentration for emerged and floating macrophytes. To obtain the field parameters, the species were collected from different locations and periods, aiming to diverse the environmental conditions which should improve the final model. However, the lack of enough infestation due to the water treatments using algaecide in the reservoirs led the study to diversify the way of sampling. So, the locations of collection were: three reservoirs in the State of São Paulo, Brazil (Paraitinga, Biritiba and Guarapiranga); Guaratuba river inside the Bertioga Restinga State Park (BRSP); some individuals were purchase at garden stores; and some from cultivation developed in a greenhouse. The greenhouse cultivation consisted of water tanks to each species, with application of a nutrient solution (every 15 days), water circulation and filtration system for no algae growth. The collection of species in all these places occurred from August 2017 to November 2018 , totaling 30 samples of $S$. auriculata, 30 of $P$. stratiotes, 23 of E. crassipes and 7 of $E$. azurea (Table 1).

The plants were sampled using the square method, size $0.25 \mathrm{~m} \times 0.25 \mathrm{~m}$ (Pompêo 2017), and carried out in boxes with water to the laboratory in the same day until the radiometric measurement (reflectance) was made. The measure was taken under controlled light conditions provided by a 1000-watt halogen lamp, positioned nearly $1 \mathrm{~m}$ from the sample and previously heated. This lamp simulates the natural conditions of the sun. After calibration of the program with white and black plates, the reflectance percentage of each specie was measured using the Ocean Optics ${ }^{\circledR}$ spectroradiometer (USB4000 model), 
with a sensor, positioned at a height of $25 \mathrm{~cm}$ from the sample, that detects and measures the radiation that leaves the plant's surface chasing a view angle of $24,3^{\circ}$. The measurement produces the reflectance values per wavelength $(\mathrm{nm})$ almost continuously, allowing the creation of graphs for each sample called spectral curves. The plants were positioned in glass vats simulating the same position that appear in the field. Therefore, the radiometric reading using the spectroradiometer correspond to the same reading registered by the satellite in natural conditions: only from the reflectance of the aerial part of the plants. Under infestation conditions, the plants form "crowded mats" on the water surface, making it impossible to observe the interference of their submerged parts (e.g. stem, root), water or soil in the reflectance observed by the sensor remotely located on the satellite.

After the radiometric measurements (reflectance data), the plants were separated into aerial and submerged fractions and the fresh and dry weights $\left(60^{\circ} \mathrm{C}\right)$ were obtained. With the high and the angle of the radiometric sensor from the sample, the area and the fresh biomass of the aerial part "read" by the spectroradiometer was determined to calculate the plant density $\left(\mathrm{g} / \mathrm{m}^{2}\right)$ for each sample. The same was done for nitrogen concentration to determine the sensor's area of view in $\mathrm{g} / \mathrm{m}^{2}$. After drying, the leaves were ground with a Wiley mill to pass through a 1-mm mesh screen. Dried and ground leaves were analyzed for chemical composition, prepared for nitrogen analysis of foliar $\mathrm{N}$ concentration following the method of Kjeldahl (1883).

The reflectance data, obtained through radiometric measurement, were segmented according to the band's width (range) of the satellite Sentinel-2 (10m pixel - bands 2, 3, 4 and 8; and 20m pixel - bands 5, 6, 7 and 8b), ranging from 400 to $900 \mathrm{~nm}$. Regions smaller and larger than these values $(150-300,1800$ 1950 and $2400-2500 \mathrm{~nm}$ ) were discarded due to the strong absorption and noise of water and atmosphere (Wang et al. 2016). This satellite has two spectral bands in the Red edge region and three in the near infrared (NIR), used in vegetation studies and now tested for aquatic macrophytes (Table 2).

From the average reflectance values collected from each sample based on the bands range from Sentinel-2, equations of biomass and nitrogen concentration using reflectance obtained in laboratory were calculated with all spectral bands using simple linear regression. First, the aim is to obtain a general mathematical model to estimate biomass and nitrogen concentration in future orbital images for the main species of emerged and floating invasive aquatic plants. Second, using the reflectance of each specie, based on Sentinel-2 bands range, the aim is to test know vegetation indices in aquatic plants, checking the possibility to estimate biomass and nitrogen concentration in infestation conditions from orbital images without the need of collection field. Therefore, four VI and two NI, reviewed by Wang et al. (2016), were used to calculated these parameters in aquatic plants through regression analysis. All Vls used RedEdge, Red, Green and NIR bands. One NI used Blue and Red Edge and the other NI used Blue, Red Edge and NIR (Table 3).

Analysis of variance (ANOVA) were used to identify (statistically significant $-a=0.05$ ) windows of spectral reparability from reflectance between the aquatic plant species. Also, between the $\mathrm{VI}$ and $\mathrm{NI}$ indices of each species based on Sentinel-2 bands. 
Aparicio (2007) calculated the Red Edge Position of twelve macrophytes using radiometric data obtained in laboratory through the interpolation and derivative methods, in order to simulate their spectral signatures registered by satellites. The Red Edge values species specific were used in this study to improve the mathematical models and the indices tests, and are presented in Table 4. According to the author, all species studied here can be observed from the same Sentinel-2 RedEdge band (RE1). The analysis of variance (ANOVA) test was also used to show the differences between the RedEdge of each species. Aparicio (2007) calculated the RedEdge for Salvinia molesta, and in this study it was used Salvinia auriculata. Despite being different species, they present very similar spectral curves, differentiating them from other species of floating aquatic plants.

\section{Results}

\subsection{Spectral curves}

The radiometric measure of each sample was performed to describe the spectral curve using samples from several places and dates, showing a great diversification of data for the estimate equations. The average of the collected curves and the percentage of reflectance for each species are shown in Figure 1. The analysis of variance tests show that the curves are different among species $(F=277.07 ; p=0.01)$. The $P$. stratiotes and E. crassipes species presented the higher values in the RedEdge and NIR region. In addition to $E$. crassipes showing such prominence, it is also the species with the highest peak in the green region, separating it from the other plants. S. auriculata and E. azurea showed similar spectral behavior in the visible bands (blue, green and red), separating only in the RedEdge (RE1 e RE2) and NIR bands.

\subsection{Biomass equation}

The predictive model for each species separately did not show significant results, therefore, the biomass equation brings all species to create a model that is unique for emerged and floating aquatic plants. Thus, to estimate the fresh biomass of emerged and floating macrophytes from radiometric measurements the combination of all spectral bands was used and equation 1 was defined as the estimation model. The regression coefficient was $\mathrm{R}^{2}=0.64(p<0.05)$, showing that it is possible to estimate biomass using the plant reflectance (Figure 2):

$$
y=44.41 x+160.45
$$

The spectral bands were tested separately to check which ones had the best result and regression coefficients to biomass estimation (Table 5). The bands of Red $\left(R^{2}=0.41\right)$ and RedEdge $\left(R^{2}=0.43\right)$ presented significant values, but only for $E$. crassipes (Figure $3 \mathrm{a}, \mathrm{b}$ ). The results for the other species are not significant. 


\subsection{Biomass indices}

The biomass indices ( $\mathrm{VI}$ ) from literature (Table 2) were applied for each species, and the values range of the best indices are shown in Figure $4(a, b)$. These values can be used in image classification to recognize these species infestation in water bodies using orbital image. The relation between indices and biomass values of each specie separately is described in Table 6 . The indices that showed better regression values for all species were NDVI $\left(R^{2}=0.24\right)$ and $R V I\left(R^{2}=0.31\right)$ and the separation of the groups are show in Figure $5(a, b)$. However, these values are not significant, so it is not possible to use in measuring biomass of emerged and floating macrophytes. The species with the best coefficient was $E$. crassipes, using the NDVI index $\left(R^{2}=0.22\right)$, but also with a low value of coefficient.

The Red Edge reflectance of each specie based on Aparicio (2007) interpolation method was used to test the relation with green biomass using linear regression. The average was also used do verify the species difference using ANOVA. Although the results for regression analysis were not significant, the results from ANOVA showed that Red Edge separated the species and can be use in the vegetation indices to identify these aquatic plants species $(F=20.96 ; p<0.05)$ (Figure 6).

Using these new narrow band, the vegetation indices $(\mathrm{VI})$ were also calculated for each species and then compared using ANOVA to check if they can be used with emerged and floating aquatic plants. The results show that the NDVI index, using the RE1 band, is different among the species and can be used to identify them in a future orbital image $(F=4.3 ; p<0.05)$ (Table 7$)$.

\subsection{Nitrogen equation}

To estimate the $\mathrm{N}$ concentration of emerged and floating macrophytes using radiometric measurements, the combination of all spectral bands was used to define equation 2 , with regression coefficient $R^{2}=0.60$ $(p<0.05)$, which suggests that it is possible to estimate the $\mathrm{N}$ concentration of aquatic plants from reflectance (Figure 7).

$$
y=0.0045 x+0.3153
$$

The spectral bands of the Blue, Near Infrared (NIR) and RE1 were tested separately to check which had the best regression coefficient (Table 8). There were no significant results, except for $E$. azurea in the Blue region $\left(R^{2}=0.53 ; p<0.05\right)$. Only with the intersection of all spectral bands is it possible to estimate the aquatic plants $\mathrm{N}$ concentration from reflectance.

\subsection{Nitrogen indices}

The nitrogen indices described in the literature (Table 2) were tested for all species and then separately (Table 9). The index with the best regression coefficient for all species was NI_Wang $\left(R^{2}=0.24\right)$. However, 
this value is not significant to estimate the $\mathrm{N}$ concentration of emerged and floating macrophytes from NI_Wang index. The differences among the nitrogen indices (NI) were not calculated using ANOVA since they were not significant to estimate nitrogen concentration in emerged and floating aquatic plants.

Nevertheless, the values range for each nitrogen index is shown in Figure $8(a, b)$. These values can be use in a future image classification to recognize the species in an infestation condition in water bodies based on nitrogen using orbital image, but not for estimate it concentration.

\section{Discussion}

\subsection{Spectral curves}

The curves obtained in this study showed that there is a reflectance difference among species, as already suggested by Aparicio and Bitencourt (2015). The mainly differences were in the regions of Green (525 $\mathrm{nm}$ to $595 \mathrm{~nm}$ ), Red (635 nm to $695 \mathrm{~nm})$, Near Infrared - NIR (727 nm to $957 \mathrm{~nm}$ ) and Red Edge (680 - 750 $\mathrm{nm})$, proving the spectral signature species specific of emerged and floating macrophytes.

When it comes to vegetation, the NIR region presents small absorption and higher reflectance, because it is the result of the incident energy interaction with the structure of the mesophyll that is the internal structure of the leaf. Maximum absorption occurs in the red region, in which chlorophyll absorbs electromagnetic radiation (Ponzoni et al. 2012, 2015). The differences in the leaf structure of each species, as well as in the concentration of photosynthetic pigments in the leaf, create differences in the reflectance that will be read by the satellite sensor, as observed by the spectroradiometer in this study. Therefore, it is possible to use this information to recognize an aquatic plant species using radiometric data obtained from an orbital image. Peñuelas et al. (1993) observed that species of emerged and floating aquatic plants show greater distinction in the limits of Red and NIR than submerged plants, facilitating this differentiation.

Absorption by all pigments occurs in the Blue region ( $425 \mathrm{~nm}$ to $500 \mathrm{~nm}$ ), so it has low reflectance values and it is difficult to discriminate species. In the green region, there is a peak of reflectance at $550 \mathrm{~nm}$ due to the lower absorption in this region, which configures the green color of the leaves. The Red Edge region also shows high reflectance values in emerged and floating, showing that this new and narrow band is important in the recognition and collection of vegetation data, and can also be used for aquatic plants (Cho and Skidmore, 2006).

\subsection{Biomass}

The vegetation indices described in the literature (NDVI, RVI, TVI and RDVI) could be improved by using the Red Edge band since each species may have different Red Edge Position, as showed by Aparicio and Bitencourt (2015). Using only Red and NIR bands (strong absorption and maximum reflectance respectively) the results was not good as expected. The greatest correlation found here between biomass 
and reflectance are associated with substituting band Red $\left(R^{2}=0.41\right)$ to band Red Edge $\left(R^{2}=0.43\right)$ for the $E$. crassipes species.

Song and Park (2020) showed a clearly difference between aquatic plants and water surface using NDVI, concluding that is the most effective vegetation indices for detecting aquatic plants. However, the separation between species is more complicated. Peñuelas et al. (1993) found that NDVI was not able to separate floating from emerging plants, explaining that the species show great variation in density and vigor. Therefore, it was only possible to classify biological groups through multivariate analyzes and new combinations of narrow spectral bands, as was observed in the present study with Red Edge band. Zhou et al. (2018) argue that the NDVI index varies with spatial and temporal changes due to the influence of vegetation groups. However, in similar types of vegetation, as the studied plants, the index can be invariable and undefined (Chen et al. 2012), requiring the use of narrower bands.

The NDVI index was derived from the NIR and Red regions. If the total photosynthetically biomass increases, the reflectance in the Red decreases and in the NIR increases (Dusseux et al. 2015). However, some studies show that broad spectral bands of NDVI can be unstable, varying with soil color, canopy structure, optical leaf properties and atmospheric conditions (Middleton, 1991; Qi et al. 1995). In addition, the index reaches a saturation level after reaching high values of biomass or leaf area (Gao et al. 2016). That is why studies have shown a non-linear relationship between NDVI and vegetation properties, due to this saturation over densely vegetated areas (Edirisinghe et al. 2011; Viña et al. 2011). This is because the use of broad spectral bands results in the loss of critical information available in specific narrow bands (Thenkabail et al. 2000), as Red Edge band.

Ullah et al. (2012) also found no significant results when correlating biomass indices with grass spectroradiometry (low and non-explanatory regression coefficients). For biomass, they also explain that saturation can difficult the estimation in smaller plants with condensed behavior, as seen in emerged and floating macrophytes. The band depth analysis parameters calculated with narrow band sensors were more accurate predictors of biomass than the NDVI index with Red and NIR bands (Mutanga and Skidmore 2004; Chen et al. 2009). Carvalho et al. (2013) also agree that satellite signal saturation is a problem for a precise relation between indices and forest structure. The explanation for the saturation problem is that, from a leaf area index of 3 , the amount of red light around $660-680 \mathrm{~nm}$ that can be absorbed by the leaves and reaches a peak. The reflectance of the NIR continues to increase due to the multiple dispersion effects (Kuman et al. 2001). This imbalance between the saturation of the red-light absorption and the high reflectance of the NIR results in a slight change in the NDVI, resulting in poor relations with biomass (Mutanga and Skidmore 2004). A vegetation cover rate above $60 \%$ shows that the indices using the NIR region are not perceptible to changes in vegetation (Gitelson et al. 2002; Glenn et al. 2008), which it may have occurred with emerged and floating macrophytes from having a dense vegetation cover.

Obtaining data directly from the field is a challenge since several environmental conditions can influence the results. Rotta et al. (2018) found a strong similarity between the curves based on in situ data and 
those based on image data (using SPOT-6), but with a slight underestimation in the field model. They discuss that the low number of sampling points $(n=8)$ used in calibration may not be sufficient to build a robust prediction model or greater sensitivity of $\mathrm{R}^{2}$. This issue was tested in the present study and better results were founded using a greater number of samples from different places. Despite the difficulties in estimating submerged aquatic heights from waterbodies due to their optical complexities, Rotta et al. (2018) discuss that the results provide useful initial evidence that it may be possible to use existing radiative transfer models to map them with adequate accuracy.

The literature indices require only two bands and can be limited to explore the rich information contented in the hyperspectral data. Then, multiple linear regression based on more than two hyperspectral bands has been used to predict vegetation parameters, such as leaf nutrient and biomass (Curran et al. 2001; Ni et al. 2020. However, multiple regression with hyperspectral data can suffer with multicollinearity (De Jong et al. 2003), so better results were observed when all spectral bands were combined to estimate biomass and when Red Edge band was used to identify species, even using simple linear regression.

\subsection{Nitrogen}

Several studies use orbital images to estimate nitrogen concentration in vegetation (Martin and Aber, 1997; Townsend et al. 2003; Smith et al. 2002; Ferwerda et al. 2005; Yu et al. 2014). But there are no studies that use reflectance data obtained from the field to estimate the foliar nitrogen concentration, creating a reliable model to use in orbital images when an infestation aquatic plants condition is observed. This study showed that the equation to estimate nitrogen concentration for emerged and floating macrophytes presented better results with the combination of all spectral bands $\left(R^{2}=0.60\right)$ than the indices presented in the literature with selected bands. Ullah et al. (2012) also found no significant results when correlating $\mathrm{N}$ estimation indices with grass spectroradiometry. Some studies discuss what the best spectral range to predict the concentration of leaf $\mathrm{N}$ is ranging from $700 \mathrm{~nm}$ to $750 \mathrm{~nm}$ (Kupiec and Curran 1995), $720 \mathrm{~nm}$ to $780 \mathrm{~nm}$ (Yoder and Pettigrew-Crosby, 1995) and up to $1640 \mathrm{~nm}$ (Martin and Aber, 1997). The Blue region (425-555 nm) was the spectrum most influenced by the concentration of $\mathrm{N}$, however, only for $E$. azurea. Studies explain that the molecular vibration that occurs around the $550 \mathrm{~nm}$ is caused by the presence and abundance of chlorophylls $a$ and $b$, which is related to the concentration of $\mathrm{N}$ (Hansen and Schjoerring 2003; Towsend et al. 2003; Yu et al. 2014).

However, for emerged and floating macrophytes, the results show that the combination of all bands is more efficient than the indices that use specific bands. Ferwerda et al. (2005) also founded that the correlation between $\mathrm{N}$ concentration and hyperspectral measurements was greater when the indices used all ranges of the spectrum than that using only Red and NIR ranges. The N indices (N_Wang and N_Tian) were not significant to estimate the concentration of $\mathrm{N}$ in emerged and floating macrophytes, as well as failing to estimate $\% \mathrm{~N}$ for crops (Wang et al. 2016). 
The species collected in this study belong to the same biological group (floating aquatic plant, except for E. azurea that is emerged aquatic plant) (Esteves 2011). Ferwerda et al. (2005) observed that indices commonly used to determine $\mathrm{N}$ concentration can be explanatory or not, depending on the type of plant (grasses, willows, olive trees, and others), which demands more specific models. Wang et al. (2016) also found no significant difference in the concentration of $\mathrm{N}$ between species that belong to the same functional type. It should be considered that there is a variation in the concentration of $\mathrm{N}$ that can occur within the species in response to differences in soil properties and history of environmental variations (Smith et al. 2002). Therefore, the variation of $\mathrm{N}$ between biological and functional types can be better explained than between species.

In addition, spectral and field information from one location may not be representative for another. Other factors can also influence variations in reflectance, such as age, uniformity and canopy layout (Martin and Aber 1997; Towsend et al. 2003). Therefore, it is important that the calibration of a model is based on data from different locations and periods of field collection, producing an equation that is predictive for emerged and floating macrophytes in general, regardless of age and conditions in which populations are found. It is important to develop an equation that works in multiple scenes without having to collect data for each specific location (Martin and Aber, 1997), as was showed in this study.

Nitrogen is not easily detected through vegetation indices. Estimating the biochemical parameters of broad-band sensors is more challenging than biophysical parameters. The chemical composition of a target is masked by the average effect of the width of a wide spectral band (Ullah et al. 2012), in addition

to broadband scanners losing absorption by N (Ferwerda et al. 2005), making the biochemistry prediction more difficult. The variation of $\mathrm{N}$ concentration is so subtle that it may have no effect on reflectance (Ullah et al. 2012; Yu et al. 2014). However, using a sensor with narrower spectral bands, such as Sentinel2 , and a model with all its spectral bands based on field measurements, it was possible to found an equation capable to estimate the $\mathrm{N}$ concentration for emerged and floating macrophytes, what before on a spatial scale was a challenge.

\section{Conclusions}

This study shows that:

- Emerged and floating aquatic plant species presents differences in their reflectance, allowing specie specific spectral curves that can be useful to estimate vegetation measurements.

- It is possible to estimate the biomass and nitrogen concentration of emerged and floating aquatic macrophytes using reflectance obtained in the field and measured in the laboratory with spectroradiometer, through equations developed with all spectral bands.

- The mathematical models had a good accuracy and are capable to estimate the parameters biomass $\left(R^{2}=0.64\right)$ and nitrogen concentration $\left(R^{2}=0.60\right)$ as a non-destructive collection method, without using time-consuming, labour-intensive and more expensive ground-based measurements. 
- The Red Edge narrow band showed to be better for calculate vegetation indices for aquatic plants, proving that more advanced multispectral sensor with narrow bands presents a valuable data-source for the accurate mapping of invasive species.

- The equations to estimate biomass and nitrogen concentration obtained from all species may simulate a natural situation in which several species can be mixed when observed by orbital sensor.

- The indices presented in the literature did not show satisfactory results for estimating the parameters, perhaps because they only use the selection of some broad bands for measurements that are subtle and difficult to perceive reflectance.

- The simulation using the range of spectral bands of satellite Sentinel-2 and the field data open a good possibility for future studies using orbital images. The orbital images can become quite useful considering that the nowadays satellites can have excellent radiometric resolutions, giving a good subsidy for the use of orbital remote sensing in limnology.

- The findings of this study underscore the relevance of the new generation multispectral sensors in providing primary data-source required for mapping biomass and nitrogen concentration at lower or no cost over time and space through reflectance, providing necessary insight and motivation to the remote sensing community, ecologists and environmentalists.

Collecting biomass samples in the field is quite challenging. Using satellite-based models could be the only viable way, in terms of cost and temporal frequency, to perform periodic collection of plants in waters which can significantly aid in ecosystem management. Although the initial results presented in this study are encouraging, the method needs to be further evaluated across different species and various other waterbodies to test its robustness.

\section{References}

1. Aparicio C (2007) Analysis of the spectral response of macrophyte species. Dissertation, University of São Paulo

2. Aparicio C, Bitencourt MD (2015) Spectral Response of Aquatic Macrophytes. In: Pompêo MLM (ed) Ecology of Reservoirs and interfaces, 1st edn. São Paulo, Brasil, pp 177-189

3. Barbosa JM, Melendez-Pastor I, Navarro-Pedreño J, Bitencourt MD (2014) Remotely sensed biomass over steep slopes: An evaluation among successional stands of the Atlantic Forest, Brazil. ISPRS J Photogramm. https://doi.org/10.1016/j.isprsjprs.2013.11.019

4. Carvalho FDAG, Barbosa JM, Bitencourt MD (2013) Modeling forest canopy closure using vegetation index. Anais XVI SBSR - INPE

5. Chen J, Gu S, Shen M, Tang Y, Matsushita B (2009) Estimating aboveground biomass of grassland having a high canopy cover: an exploratory analysis of in situ hyperspectral data. Int J Remote Sens. https://doi.org/10.1080/01431160902882496

6. Chen J, Wang L, Li Y, Zhang W, Fu X, Le Y (2012) Effect of Spartina alterniflora invasion and its controlling technologies on soil microbial respiration of a tidal wetland in Chongming Dongtan, 
China. Ecol Eng. https://doi.org/10.1016/j.ecoleng.2012.01.024

7. Cho MA, Skidmore AK (2006) A new technique for extracting the red edge position from hyperspectral data: The linear extrapolation method. Remote Sens Environ. https://doi.org/10.1016/j.rse.2005.12.011

8. Clevers JGPW, De Jong SM, Epema GF, Van Der Meer FD, Bakker WH, Skidmore AK, Scholte KH (2002) Derivation of the red edge index using the MERIS standard band setting. Int J Remote Sens. https://doi.org/10.1080/01431160110104647

9. Coelho FF, Lopes FS, Sperber CF (2005) Persistence strategy of Salvinia auriculata Aublet in temporary ponds of Southern Pantanal, Brazil. Aquat Bot.

https://doi.org/10.1016/j.aquabot.2005.02.001

10. Curran PJ, Dungan JL, Peterson DL (2001) Estimating the foliar biochemical concentration of leaves with reflectance spectrometry: testing the Kokaly and Clark methodologies. Remote Sens Environ. https://doi.org/10.1016/S0034-4257(01)00182-1

11. Dash J, Curran PJ (2007) Evaluation of the MERIS terrestrial chlorophyll index (MTCI). Adv Space Res. https://doi.org/10.1016/j.asr.2006.02.034

12. De Jong SM, Pebesma EJ, Lacaze B (2003) Above-ground biomass assessment of Mediterranean forests using airborne imaging spectrometry: the DAIS Peyne experiment. Int J Remote Sens. https://doi.org/10.1080/01431160210145560

13. Dube T, Mutanga O, Sibanda M, Bangamwabo V, Shoko C (2017) Evaluating the performance of the newly-launched Landsat 8 sensor in detecting and mapping the spatial configuration of water hyacinth (Eichhornia crassipes) in inland lakes. Zimbabwe Phys Chem Earth. https://doi.org/10.1016/j.pce.2017.02.015

14. Dusseux P, Hubert-Moy L, Corpetti T, Vertès F (2015) Evaluation of SPOT imagery for the estimation of grassland biomass. Int J Appl Earth Obs. https://doi.org/10.1016/j.jag.2014.12.003

15. Edirisinghe A, Hill MJ, Donald GE, Hyder M (2011) Quantitative mapping of pasture biomass using satellite imagery. Int J Remote Sens. https://doi.org/10.1080/01431161003743181

16. Esteves FDA (2011) Fundamentals of Limnology. Rio de Janeiro, Brasil

17. Ferwerda JG, Skidmore AK, Mutanga O (2005) Nitrogen detection with hyperspectral normalized ratio indices across multiple plant species. Int J Remote Sens.

https://doi.org/10.1080/01431160500181044

18. Gao JH, Feng ZX, Chen L, Wang YP, Bai F, Li J (2016) The effect of biomass variations of Spartina alterniflora on the organic carbon content and composition of a salt marsh in northern Jiangsu Province, China. Ecol Eng. https://doi.org/10.1016/j.ecoleng.2016.06.088

19. Gitelson AA, Kaufman YJ, Stark R, Rundquist D (2002) Novel algorithms for remote estimation of vegetation fraction. Remote Sens Environ. https://doi.org/10.1016/S0034-4257(01)00289-9

20. Glenn EP, Huete AR, Nagler PL, Nelson SG (2008) Relationship between remotely-sensed vegetation indices, canopy attributes and plant physiological processes: What vegetation indices can and cannot tell us about the landscape. Sensors. https://doi.org/10.3390/s8042136 
21. Ghosh S, Mishra DR, Gitelson A (2016) Long-term monitoring of biophysical characteristics of tidal wetlands in the northern Gulf of Mexico-a methodological approach using MODIS. Remote Sens Environ. https://doi.org/10.1016/j.rse.2015.11.015

22. Gong P, Pu R, Biging GS, Larrieu MR (2003) Estimation of forest leaf area index using vegetation indices derived from Hyperion hyperspectral data. IEEE T Geosci Remote. https://doi.org/10.1109/TGRS.2003.812910

23. Hansen PM, Schjoerring JK (2003) Reflectance measurement of canopy biomass and nitrogen status in wheat crops using normalized difference vegetation indices and partial least squares regression. Remote Sens Environ. https://doi.org/10.1016/S0034-4257(03)00131-7

24. Jampeetong A, Brix H (2009) Nitrogen nutrition of Salvinia natans: effects of inorganic nitrogen form of growth, morphology, nitrate reductase activity and uptake kinetics of ammonium and nitrate. Aquat Bot. https://doi.org/10.1016/j.aquabot.2008.06.005

25. Julien MH, Center TD, Tipping PW (2002) Floating fern (Salvinia). Biological control of invasive plants in the eastern United States, USDA Forest Service Publication: United States

26. Kjeldahl C (1883) A new method for the determination of nitrogen in organic matter. Z Anal Chem 22:366

27. Kupiec JA, Curran PJ (1995) Decoupling effects of the canopy and foliar biochemicals in AVIRIS spectra. Int J Remote Sens. https://doi.org/10.1080/01431169508954510

28. Lee KS, Cohen WB, Kennedy RE, Maiersperger TK, Gower ST (2004) Hyperspectral versus multispectral data for estimating leaf area index in four different biomes. Remote Sens Environ. https://doi.org/10.1016/j.rse.2004.04.010

29. Martin ME, Aber JD (1997) High spectral resolution remote sensing of forest canopy lignin, nitrogen, and ecosystem processes. Ecol App. https://doi.org/10.1890/1051-0761(1997)007

30. Middleton EM (1991) Solar zenith angle effects on vegetation indices in tallgrass prairie. Remote Sens Environ. https://doi.org/10.1016/0034-4257(91)90071-D

31. Motohka T, Nasahara KN, Oguma H, Tsuchida S (2010) Applicability of green-red vegetation index for remote sensing of vegetation phenology. Remote Sens. https://doi.org/10.3390/rs2102369

32. Mutanga O, Skidmore AK (2004) Narrow band vegetation indices overcome the saturation problem in biomass estimation. Int J Remote Sens. https://doi.org/10.1080/01431160310001654923

33. Ni TNK, Tin HC, Thach VT, Jamet C, Saizen I (2020) Mapping Submerged Aquatic Vegetation along the Central Vietnamese Coast Using Multi-Source Remote Sensing. ISPRS Int J Geo-Inf. https://doi.org/10.3390/ijgi9060395

34. Penatti NC, de Almeida TIR, Ferreira LG, Arantes AE, Coe MT (2015) Satellite-based hydrological dynamics of the world's largest continuous wetland. Remote Sens Environ. https://doi.org/10.1016/j.rse.2015.08.031

35. Peñuelas J, Gamon JA, Griffin KL, Field CB (1993) Assessing community type, plant biomass, pigment composition, and photosynthetic efficiency of aquatic vegetation from spectral reflectance. Remote Sens Environ. https://doi.org/10.1016/0034-4257(93)90088-F 
36. Pompêo M (2017) Monitoring and management of aquatic macrophytes in Brazilian tropical reservoirs. São Paulo, Brasil, 138 p

37. Ponzoni FJ, Shimabukuro YE, Kuplich TM (2012) Sensoriamento remoto no estudo da vegetação, 2nd edn. São Paulo, Brasil

38. Ponzoni FJ, Pacheco LRF, Santos SBD, Andrades Filho CDO (2015) Caracterização espectro-temporal de dosséis de Eucalyptus spp. mediante dados radiométricos TM/Landsat5. Cerne. https://doi.org/10.1590/01047760201521021457

39. Qi J, Moran MS, Cabot F, Dedieu G (1995) Normalization of sun/view angle effects using spectral albedo-based vegetation indices. Remote Sens Environ. https://doi.org/10.1016/00344257(95)00034-X

40. Rotta LHS, Mishra DR, Watanabe FS, Rodrigues TW, Alcântara EH, Imai NN (2018) Analyzing the feasibility of a space-borne sensor (SPOT-6) to estimate the height of submerged aquatic vegetation (SAV) in inland waters. ISPRS Journal Photogramm. https://doi.org/10.3390/rs2102369

41. Silva TSF, Costa MPF, Melack JM (2010) Spatial and temporal variability of macrophyte cover and productivity in the eastern Amazon floodplain: A remote sensing approach. Remote Sens Environ. https://doi.org/10.1016/j.rse.2010.04.007

42. Smith ML, Ollinger SV, Martin ME, Aber JD, Hallett RA, Goodale CL (2002) Direct estimation of aboveground forest productivity through hyperspectral remote sensing of canopy nitrogen. Ecol App. https://doi.org/10.1890/1051-0761(2002)012[1286:DEOAFP]2.0.CO;2

43. Song B, Park K (2020) Detection of aquatic plants using multispectral UAV imagery and vegetation index. Remote Sens. https://doi.org/10.3390/rs12030387

44. Sullivan PR, Postle LA, Julien M (2011) Biological control of Salvinia molesta by Cyrtobagous salviniae in temperate Australia. Biol Control. https://doi.org/10.1016/j.biocontrol.2011.03.009

45. Thenkabail PS, Smith RB, De Pauw E (2000) Hyperspectral vegetation indices and their relationships with agricultural crop characteristics. Remote Sens Environ. https://doi.org/10.1016/S00344257(99)00067-X

46. Tian YC, Yao X, Yang J, Cao WX, Hannaway DB, Zhu Y (2011) Assessing newly developed and published vegetation indices for estimating rice leaf nitrogen concentration with ground-and spacebased hyperspectral reflectance. Field Crop Res. https://doi.org/10.1016/j.fcr.2010.11.002

47. Townsend PA, Foster JR, Chastain RA, Currie WS (2003) Application of imaging spectroscopy to mapping canopy nitrogen in the forests of the central Appalachian Mountains using Hyperion and AVIRIS. IEEE T Geosci Remote. https://doi.org/10.1109/TGRS.2003.813205

48. Ullah S, Si Y, Schlerf M, Skidmore AK, Shafique M, Iqbal IA (2012) Estimation of grassland biomass and nitrogen using MERIS data. Int J Appl Earth Obs. https://doi.org/10.1016/j.jag.2012.05.008

49. Viña A, Gitelson AA, Nguy-Robertson AL, Peng Y (2011) Comparison of different vegetation indices for the remote assessment of green leaf area index of crops. Remote Sens Environ. https://doi.org/10.1016/j.rse.2011.08.010 
50. Wang W, Yao X, Yao X, Tian Y, Liu X, Ni J, Cao W, Zhu Y (2012) Estimating leaf nitrogen concentration with three-band vegetation indices in rice and wheat. Field Crops Res.

https://doi.org/10.1016/j.fcr.2012.01.014

51. Wang Z, Wang T, Darvishzadeh R, Skidmore AK, Jones S, Suarez L, Woodgate W, Heiden U, Heurich M, Hearne J (2016) Vegetation Indices for Mapping Canopy Foliar Nitrogen in a Mixed Temperate Forest. Remote Sens. https://doi.org/10.3390/rs8060491

52. Yoder BJ, Pettigrew-Crosby RE (1995) Predicting nitrogen and chlorophyll content and concentrations from reflectance spectra (400-2500 nm) at leaf and canopy scales. Remote Sens Environ. https://doi.org/10.1016/0034-4257(95)00135-N

53. Yu KQ, Zhao YR, Li XL, Shao YN, Liu F, He Y (2014) Hyperspectral imaging for mapping of total nitrogen spatial distribution in pepper plant. Plos One. https://doi.org/10.1371/journal.pone.0134071

54. Zhao D, Huang L, Li J, Qi J (2007) A comparative analysis of broadband and narrowband derived vegetation indices in predicting $\mathrm{LAl}$ and CCD of a cotton canopy. ISPRS J Photogramm. https://doi.org/10.1016/j.isprsjprs.2007.01.003

55. Zhou Z, Yang Y, Chen B (2018) Estimating Spartina alterniflora fractional vegetation cover and aboveground biomass in a coastal wetland using SPOT6 satellite and UAV data. Aquat Bot. https://doi.org/10.1016/j.aquabot.2017.10.004

\section{Tables}

Table 1 Sampling locations and dates for aquatic macrophytes species 
Species

Salvinia auriculata

Solvinia auniculata

Location

EEAB Channel - Biritiba

Paraitinga reservoir

Biritiba reservoir

IB/USP tank

\section{Dates}

09-08-2017 / 12-09-2017

26-10-2017

23-11-2017

12-12-2017 / 07-02-2018 / 22-02-2018 / 08-03-

2018

22-03-2018 / 09-04-2018 / 25-04-2018 / 09-05-

2018

28-05-2018 / 21-06-2018 / 02-07-2018 / 20-07-

2018

06-08-2018 / 03-09-2018

Guarapiranga reservoir

02-03-2018 / 11-05-2018

Guaratuba River (BRSP) 11-07-2018

Greenhouse cultivation

06-08-2018 / 03-09-2018 / 12-09-2018

Purchase Morumbi store

27-08-2018

Purchase Eliseu store

27-08-2018

Pistia stratiotes

EEAB channel - Biritiba

09-08-2017 / 12-09-2017

Guarapiranga reservoir

02-03-2018

Japanese Garden / IB-

USP

02-03-2018 / 04-04-2018

Greenhouse cultivation

08-03-2018 / 18-05-2018 / 21-06-2018 / 17-072018

06-08-2018 / 03-09-2018

Guaratuba River (BRSP) 11-07-2018 / 17-10-18 / 11-07-2018

Santa Lúcia farm

02-08-2018

Ibirapuera park

08-08-2018 / 27-11-2018 / 03-12-2018

Purchase Morumbi store

27-08-2018 / 06-11-2018

Purchase Eliseu store

27-08-2018 / 25-09-2018 / 06-11-2018

Eichhornia crassipes

Greenhouse cultivation

18-05-2018 / 21-06-2018 / 20-07-2018 / 03-092018

Purchase Eliseu store

27-08-2018 / 25-09-2018 / 28-09-2018 / 06-112018

Guaratuba River (BRSP) 17-10-2018 
Eichhornia azurea Guaratuba River (BRSP) 11-07-2018 / 17-10-18

Table 2 Wavelengths range $(\mathrm{nm})$ of the bands from the Sentinel-2 sensor

\begin{tabular}{ll} 
Bands & Wavelength range (nm) \\
\hline Band 2 - Blue & $425-555$ \\
\hline Band 3 - Green & $525-595$ \\
\hline Band 4 - Red & $635-695$ \\
\hline Band 8 - NIR & $727-957$ \\
\hline Band 5 - Red edge 1 & $690-720$ \\
\hline Band 6 - Red edge 2 & $725-755$ \\
\hline Band 7 - NIR & $763-803$ \\
\hline Band 8b - NIR & $845-885$ \\
\hline
\end{tabular}

Table 3 Vegetation indices $(\mathrm{VI})$ and Nitrogen indices $(\mathrm{NI})$ tested in emerged and floating aquatic plants [12] using reflectance obtained in laboratory

Index

\section{Biomass}

\section{NDVI}

(Normalized difference vegetation index)

\section{Equation}

$$
\left(R_{800}-R_{670}\right) /\left(R_{800}+R_{670}\right)
$$

Tucker et al. [7]

\section{Reference}

\section{RVI}

$$
R_{800} / R_{670}
$$

Jordan [24]

(Ratio vegetation index)

\section{TVI}

(Triangular vegetation index)

\section{RDVI}

(Renormalized difference vegetation

$$
\begin{aligned}
& 0.5\left[120\left(R_{750}-R_{550}\right)-200\left(R_{670}+\right.\right. \\
& \left.\left.R_{550}\right)\right]
\end{aligned}
$$

Broge and Leblanc [25]

$$
\left(R_{800}-R_{670}\right) /\left[\sqrt{ }\left(R_{800}+R_{670}\right)\right]
$$

Roujean and Breon [26] index)

\section{Nitrogen}

NI_Tian

NI_Wang

$$
\mathrm{R}_{705} /\left(\mathrm{R}_{717}+\mathrm{R}_{491}\right)
$$

$\left(R_{924}-R_{703}+2 R_{423}\right) /\left(R_{924}+R_{703}-\right.$ $2 \mathrm{R}_{423}$ ) 
Table 4 Red edge of macrophyte species calculated by interpolation and derivative methods, using radiometric data obtained in laboratory with spectroradiometer (Aparicio, 2007)

\begin{tabular}{lllll} 
Species & $\begin{array}{l}\text { Interpolation red } \\
\text { edge }\end{array}$ & $\begin{array}{l}\text { Standard } \\
\text { deviation }\end{array}$ & $\begin{array}{l}\text { Derivative red } \\
\text { edge }\end{array}$ & $\begin{array}{l}\text { Standard } \\
\text { deviation }\end{array}$ \\
\hline S. molesta & 701 & 3.89 & 700 & 1.87 \\
\hline $\begin{array}{l}\text { E. } \\
\text { crassipes }\end{array}$ & 715 & 1.00 & 712 & 2.33 \\
\hline E. azurea & 710 & 5.01 & 704 & 5.53 \\
\hline P. stratiotes & 706 & 2.97 & 701 & 0.52
\end{tabular}

Table 5 Determination coefficients $\left(R^{2}\right)$ calculated between macrophyte green biomass $\left(\mathrm{g} \cdot \mathrm{m}^{-2}\right)$ and Red, NIR and Red Edge reflectance. All values show $p<0.05$

\begin{tabular}{|llll|}
\hline & Red & NIR & Red edge \\
\hline & $635-695$ & $727-957$ & $690-720$ \\
\hline All species & 0.10 & 0.01 & 0.08 \\
\hline S. auriculata & 0.06 & 0.03 & 0.01 \\
\hline P. stratiotes & 0.20 & 0.15 & 0.26 \\
\hline E. crassipes & 0.41 & 0.16 & $\mathbf{0 . 4 3}$ \\
\hline E. azurea & 0.01 & 0.04 & 0.07 \\
\hline
\end{tabular}

Table 6 Determination coefficients $\left(\mathrm{R}^{2}\right)$ calculated between indices $(\mathrm{VI})$ and green biomass $\left(\mathrm{g} \cdot \mathrm{m}^{-2}\right)$ of emerged and floating macrophytes. All values show $p<0.05$ 


\begin{tabular}{|lllll|}
\hline & NDVI & RVI & TVI & RDVI \\
\hline & Tucker et al. [7] & Jordan [24] & Broge and Leblanc [25] & Roujean and Breon [26] \\
\hline All species & $\mathbf{0 . 2 4}$ & $\mathbf{0 . 3 1}$ & 0.15 & 0.003 \\
\hline S. auriculata & 0.03 & 0.005 & 0.02 & 0.003 \\
\hline P. stratiotes & 0.04 & 0.01 & 0.19 & 0.10 \\
\hline E. crassipes & $\mathbf{0 . 2 2}$ & 0.05 & 0.10 & 0.07 \\
\hline E. azurea & 0.001 & 0.01 & 0.05 & 0.03 \\
\hline
\end{tabular}

Table 7 Biomass indices (VI) using Red Edge band (based on range of Setinel-2 satellite) between macrophytes species using ANOVA. *Shows the significant statistical differences

\begin{tabular}{lll} 
Vegetation indices & F & $\boldsymbol{p}$ \\
\hline NDVI & 4.3 & $0.01^{*}$ \\
\hline RVI & 2.1 & 0.10 \\
\hline RDVI & 0.8 & 0.48
\end{tabular}

Table 8 Determination coefficients $\left(R^{2}\right)$ calculated between macrophytes $\mathrm{N}$ concentration $\left(\mathrm{g} \cdot \mathrm{m}^{-2}\right)$ and blue. NIR and Red Edge reflectance. All values show $p<0.05$

\begin{tabular}{|llll|}
\hline & Blue & NIR & Red edge \\
\hline & $425-555$ & $727-957$ & $690-720$ \\
\hline All species & 0.02 & 0.08 & 0.03 \\
\hline S. auriculata & 0.03 & 0.16 & 0.02 \\
\hline P. stratiotes & 0.04 & 0.01 & 0.14 \\
\hline E. crassipes & 0.07 & 0.17 & 0.06 \\
\hline E. azurea & $\mathbf{0 . 5 3}$ & 0.02 & 0.16 \\
\hline
\end{tabular}

Table 9 Determination coefficients $\left(R^{2}\right)$ calculated to nitrogen indices $\left(\mathrm{g} \cdot \mathrm{m}^{-2}\right)$ of emerged and floating macrophytes. All values show $p<0.05$ 


\begin{tabular}{|lll|}
\hline & NI_Tian & NI_Wang \\
\hline & Tian et al. [9] & Wang et al. [28] \\
\hline All species & 0.02 & $\mathbf{0 . 2 4}$ \\
\hline S. auriculata & 0.01 & 0.14 \\
\hline P. stratiotes & 0.04 & 0.26 \\
\hline E. crassipes & 0.17 & 0.10 \\
\hline E. azurea & 0.10 & 0.05 \\
\hline
\end{tabular}

\section{Figures}

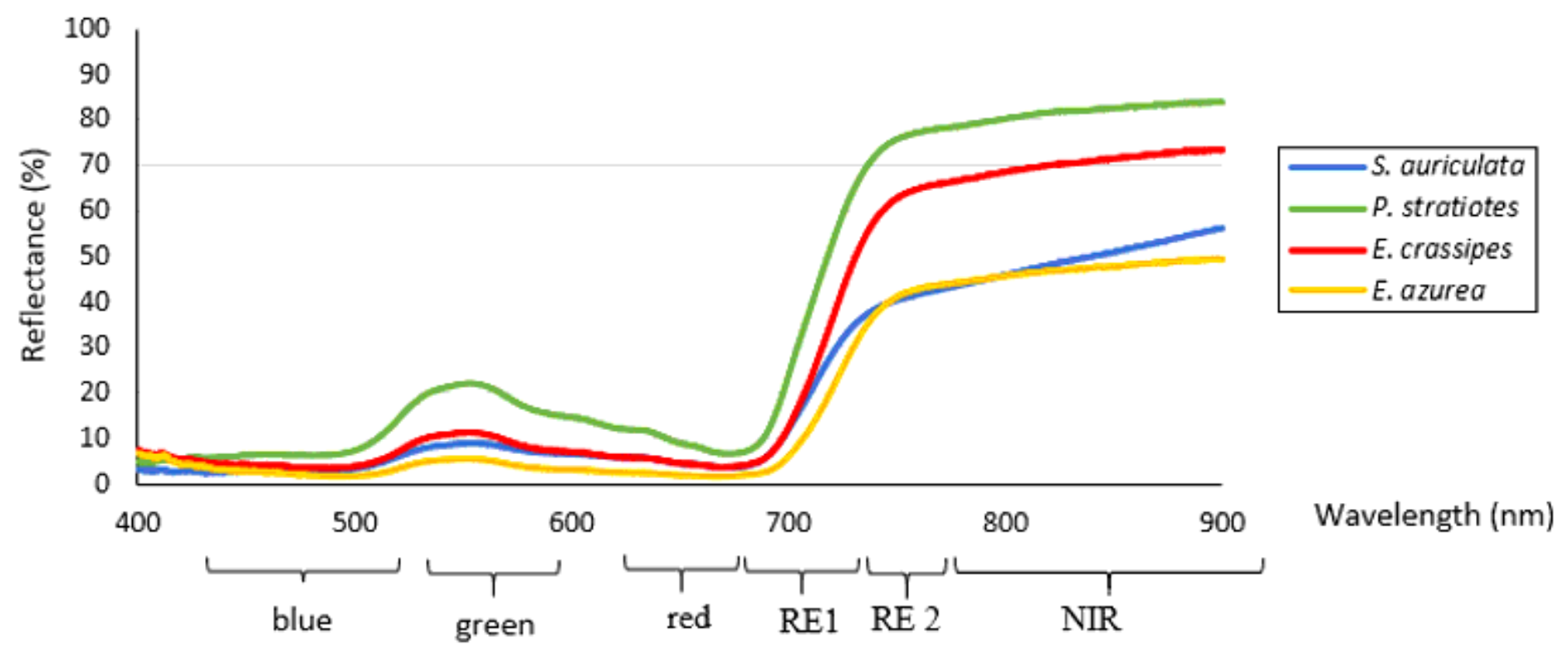

\section{Figure 1}

Spectral curve of each aquatic macrophytes species obtained with spectroradiometer (Ocean Optics ${ }^{\circledR}$ model USB4000) statistically differentiated by ANOVA $(F=277.07 ; p<0.05)$ 


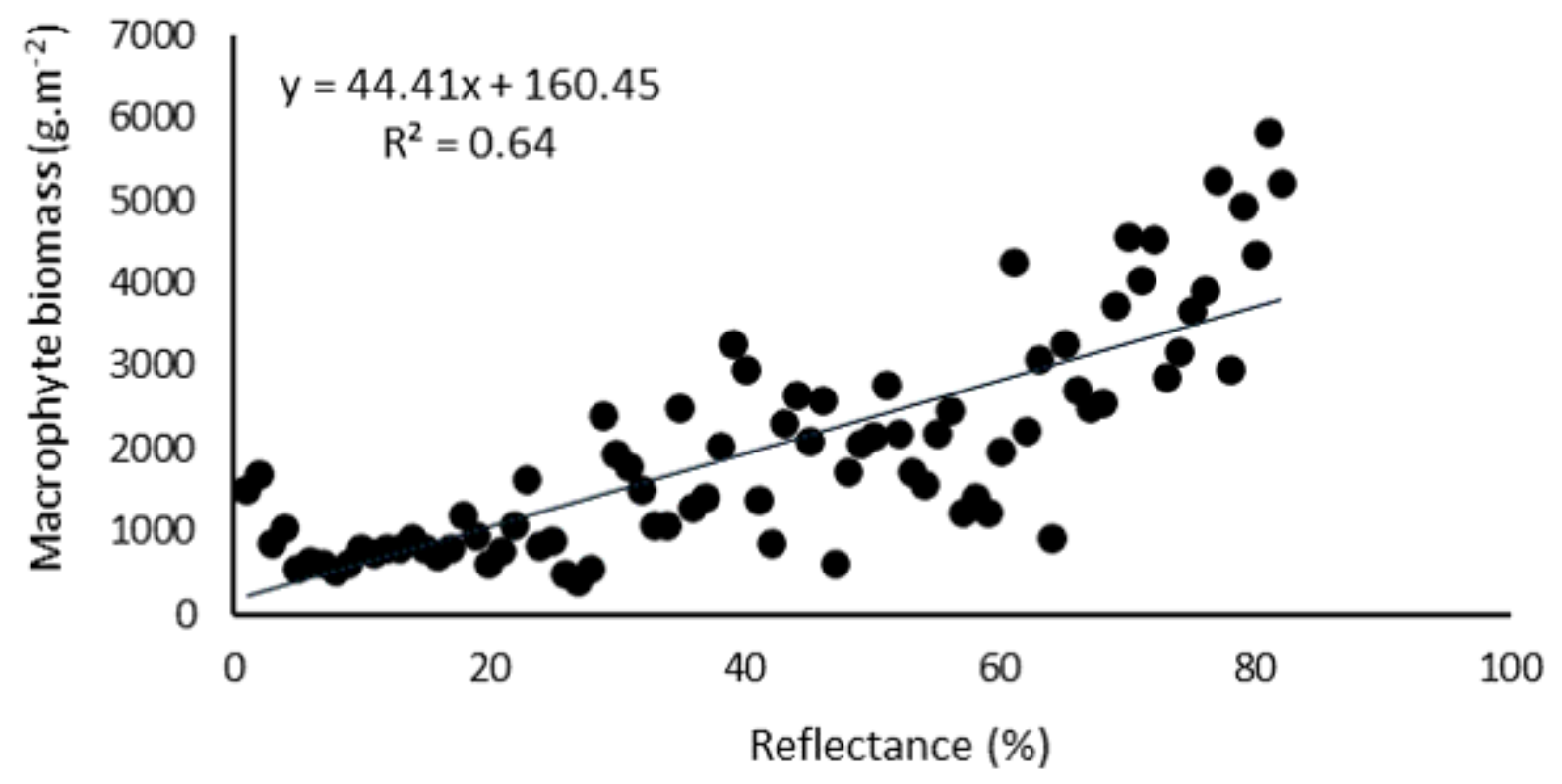

Figure 2

Linear regression calculated between macrophyte green biomass (g.m-2) and reflectance (\%) from all spectrums 

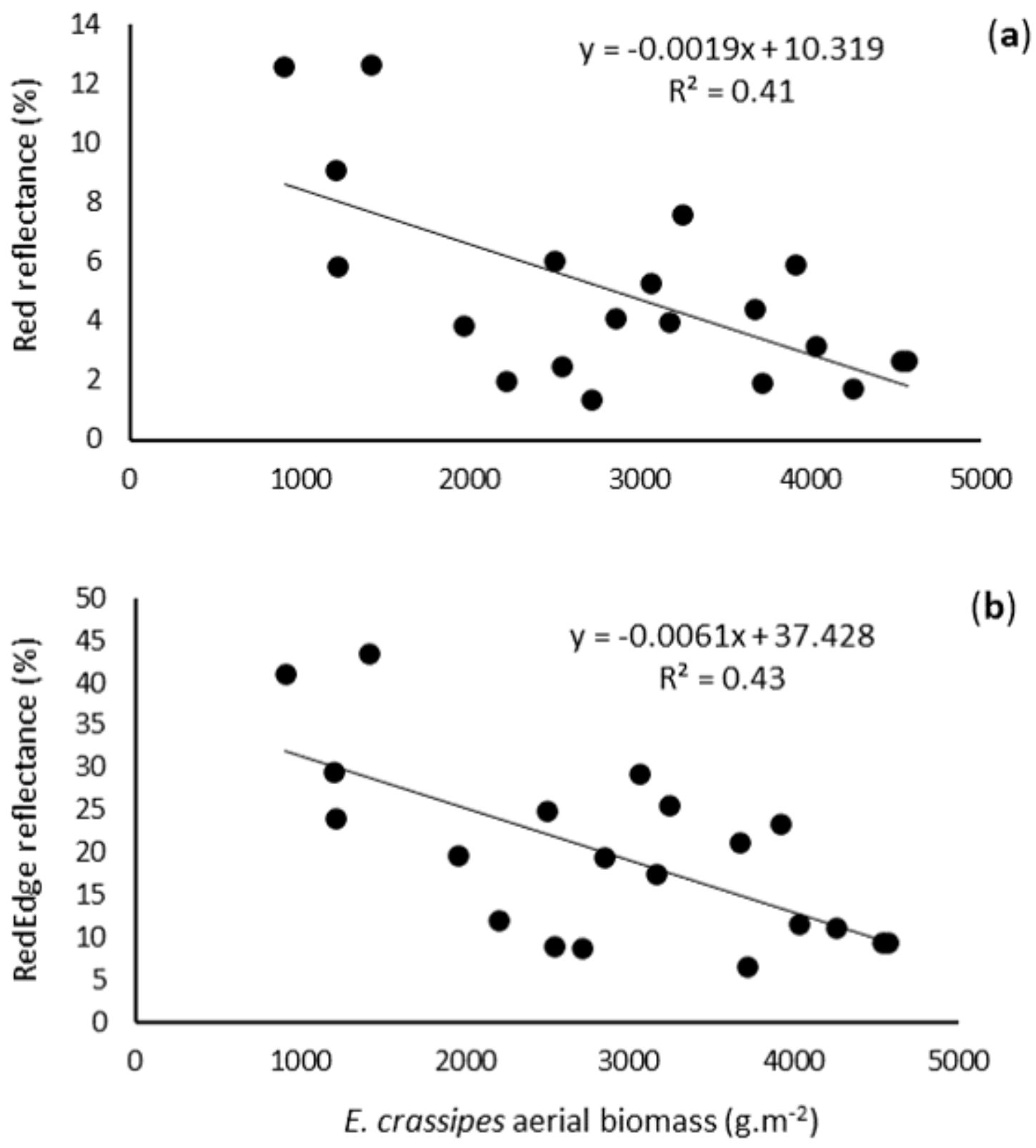

Figure 3

Linear regression calculated between E. crassipes aerial biomass (g.m-2) versus (a) Red and (b) RE1 reflectance 
(a)

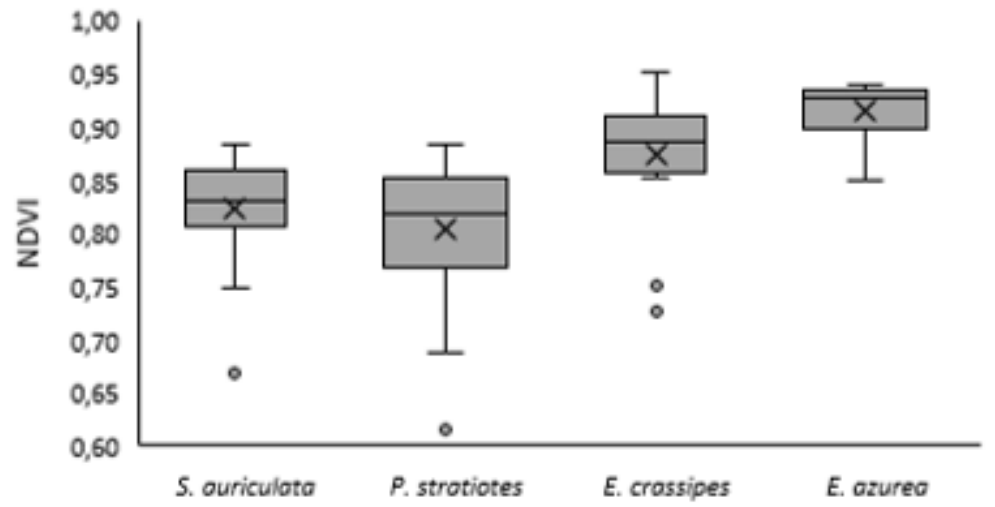

(b)

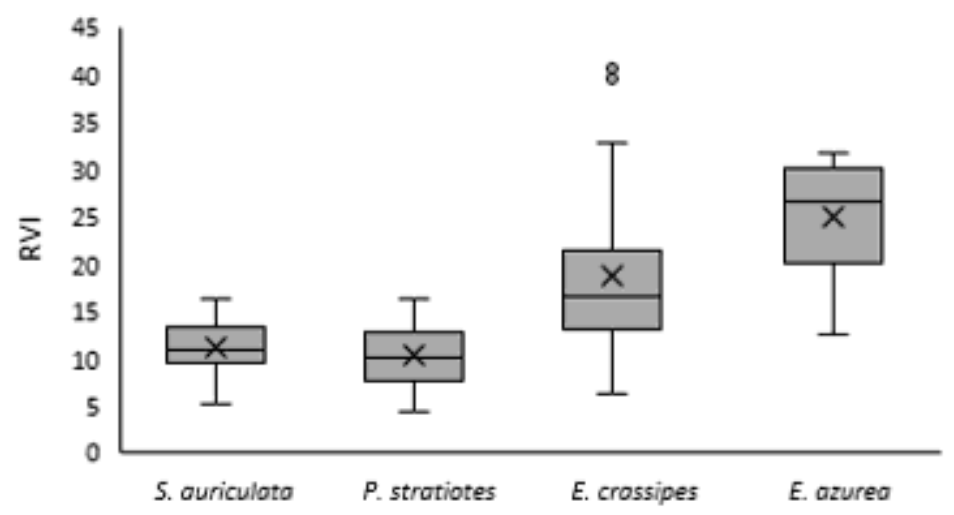

\section{Figure 4}

Indices values ranges of macrophytes species green biomass to use in remote orbital image classification: (a) NDVI and (b) RVI. The box is the interval and the bar the standard deviation 


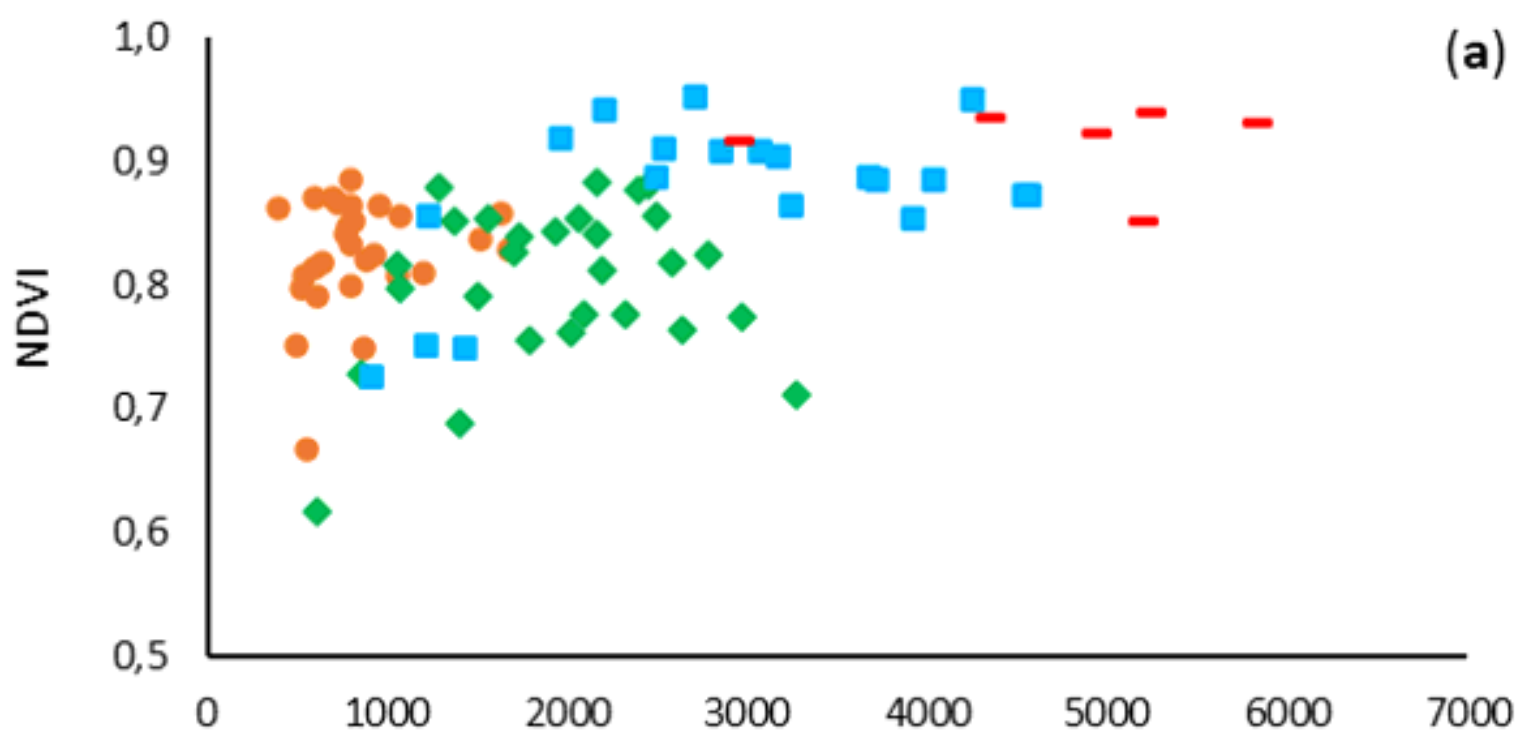

Aerial fresh biomass $\left(\mathrm{g} \cdot \mathrm{m}^{-2}\right)$

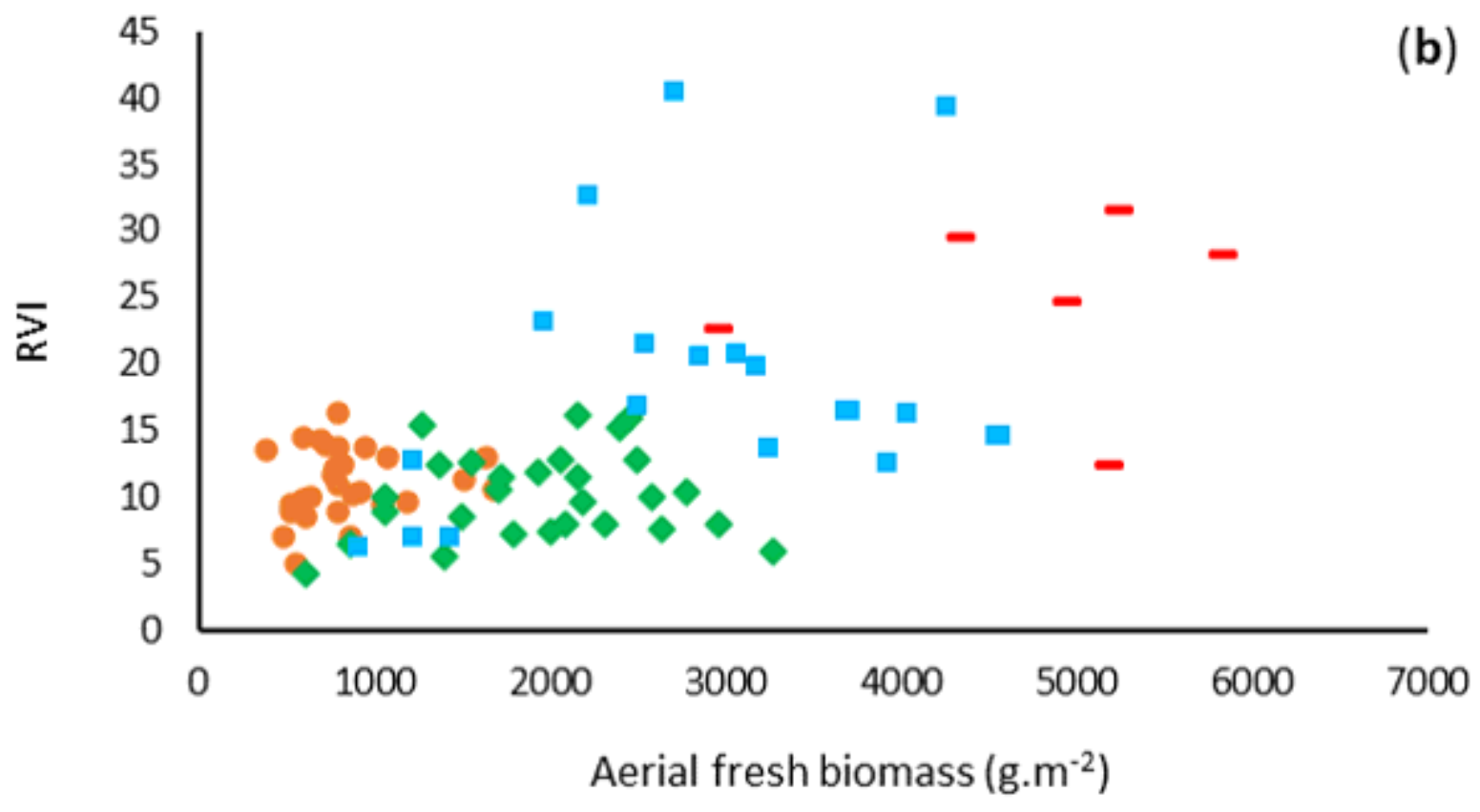

Figure 5

Scatterplot showing the separation of the emerged and floating aquatic plant species using the relation between vegetation indices and aerial fresh biomass (g.m-2): (a) NDVI and (b) RVI 


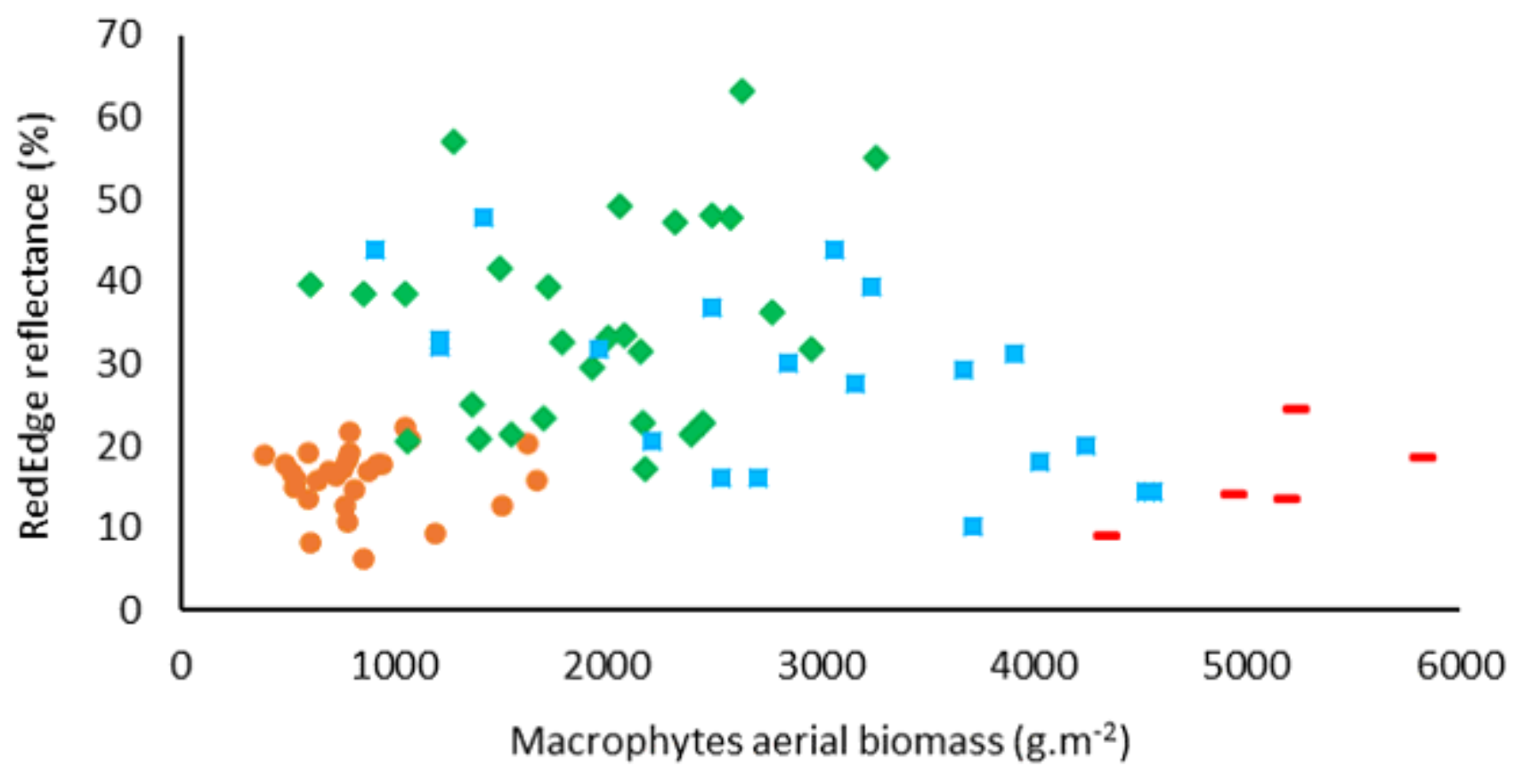

Figure 6

Scatterplot between Red Edge reflectance of macrophytes species and aerial fresh biomass (g.m-2)

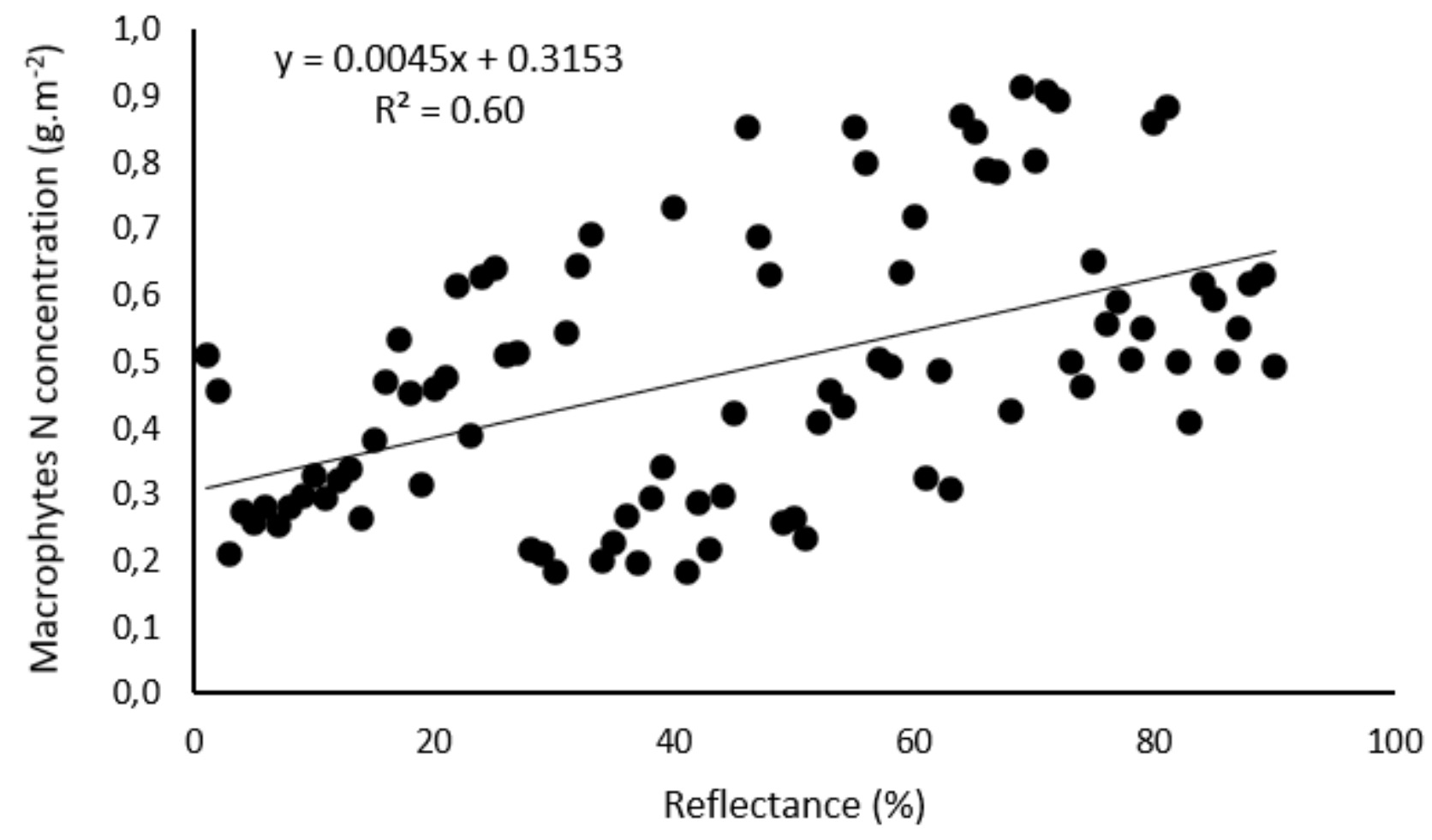

Figure 7 
Linear regression calculated between macrophytes $\mathrm{N}$ concentration (g.m-2) and reflectance (\%) using all spectral bands

(a)

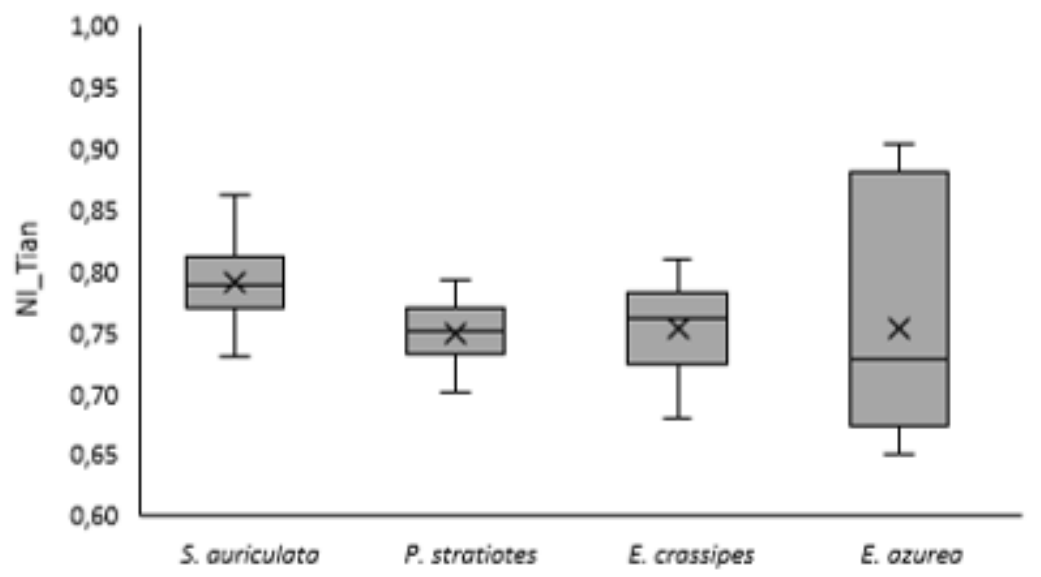

(b)

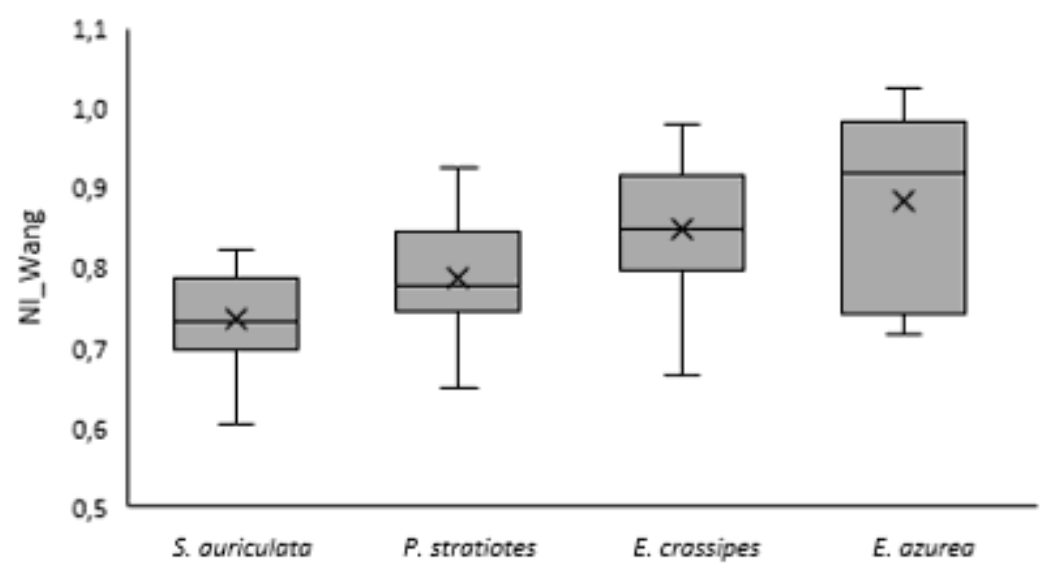

Figure 8

Indices values ranges of nitrogen concentration for all species to use in remote orbital images: (a) NI_Tian and (b) NI_Wang. The box is the interval and the bar the standard deviation 